MAURÍCIO BAPTISTELLA BUNAZAR

\title{
ANÁLISE DOGMÁTICA DA CATEGORIA JURÍDICA DA INVALIDADE NO CÓDIGO CIVIL BRASILEIRO
}

\author{
Tese de doutorado
}

Orientador: Professor Associado José Fernando Simão

FACULDADE DE DIREITO DA UNIVERSIDADE DE SÃO PAULO

SÃO PAULO - SP 


\title{
ANÁLISE DOGMÁTICA DA CATEGORIA JURÍDICA DA INVALIDADE NO CÓDIGO CIVIL BRASILEIRO
}

\author{
Tese de doutorado apresentada à Banca \\ Examinadora do Programa de Pós-Gradução em \\ Direito da Faculdade de Direito da Universidade \\ de São Paulo, realizada sob orientação do \\ Professor Associado José Fernando Simão.
}

FACULDADE DE DIREITO DA UNIVERSIDADE DE SÃO PAULO

SÃO PAULO - SP 
BUNAZAR, Maurício B. Análise dogmática da categoria jurídica da invalidade no Código Civil brasileiro. 2017. 278 p. Tese (doutorado). Faculdade de Direito da Universidade de São Paulo, 2017.

RESUMO: A tese visa a analisar dogmaticamente a categoria jurídica da invalidade à luz do Código Civil brasileiro. Com isso, pretende-se colaborar para a solução de casos concretos, seja fornecendo algum fundamento racional para a preservação do negócio jurídico, seja fornecendo critérios para sua ineficacização quando a invalidação for inevitável.

Palavras-chave: Autonomia privada. Negócio jurídico. Invalidade. Nulidade. Anulabilidade. Favor negotii. Artigo 182 do Código Civil brasileiro. 
BUNAZAR, Maurício B. Academic Analysis of the legal category of invalidity in the Brazilian Civil Code. 2017. 278 p. Thesis (doctorate). University of São Paulo, School of Law, 2017.

\begin{abstract}
The thesis aims at analyzing dogmatically the legal category of invalidity based on the brazilian Civil Code. Thus, it is intended to collaborate in the solution of concrete cases, either by providing some rational basis for the preservation of a legal transaction, or by providing criteria as how to make the transaction without any legal effect when invalidation is unavoidable.
\end{abstract}

Keywords: Private autonomy. Legal transaction. Invalidity. Nullity. Annulability. Favor negotii. Section 182 of the brazilian Civil Code. 
BUNAZAR, Maurício B. Analyse dogmatique de la catégorie juridique de l'invalidité dans le Code Civil brésilien. 2017. 278 p. Thèse (doctorat), Faculté de Droit de l’Université de São Paulo, 2017.

RESUMÉ: La thèse vise à analyser dogmatiquement la catégorie juridique d'invalidité à la lumière du Code civil brésilien. Ainsi, on veut contribuer à la solution des cas concrets, tantôt en fournissant une certaine justification pour la préservation de l'acte juridique, tantôt en fournissant des critères pour le retrait des ses effets lorsque l'invalidation est inévitable.

Mots-clés: Autonomie privée. Acte juridique. Invalidité. Nullité. Annulabilité. Favor negotii. Art. 182 do Code Civil brésilien. 
"Pois bem, coragem! Envereda nos caminhos da razão, confiando-te na piedade. $\mathrm{Na}$ verdade, nada existe que seja tão árduo e difícil que não se torne, com a ajuda divina, bem simples e fácil. E assim, orientados para Deus e implorando-lhe o auxí-lio, havemos de investigar o tema a que nos propusemos."

(Santo Agostinho, O livre-arbítrio) 


\section{SUMÁRIO}

Introdução

Capítulo 1 - A invalidade e o exercício da autonomia privada 13

1.1. Negócio jurídico e ato jurídico em sentido estrito 13

1.2. Autonomia privada 20

1.3. A invalidade do ato jurídico preceptivo como consequência do exercício irregular da autonomia privada

\section{Capítulo 2 - Fundamentos dos requisitos de validade do ato jurídico preceptivo ..... 26}

2.1. Requisitos de validade do negócio jurídico ....................................................... 26

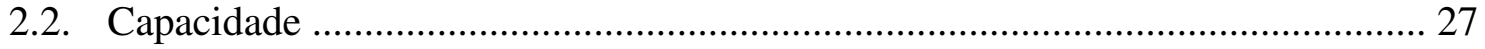

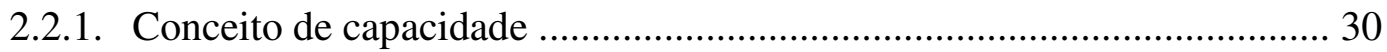

2.2.2. A idade como critério de aquisição da capacidade de agir ..................... 32

2.2.3. Fundamento da exigência de capacidade para a prática de atos jurídicos

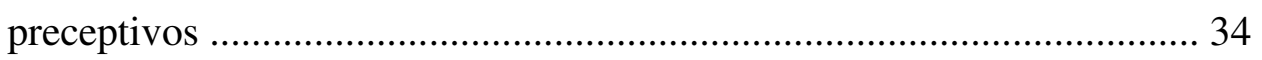

2.2.4. Contornos dogmáticos da função protetiva das incapacidades ................ 36

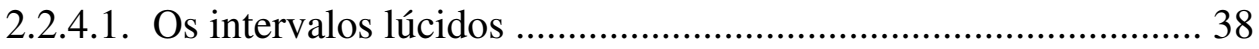

2.2.4.2. Os intervalos insanos ........................................................... 41

2.2.4.2.1. O Estatuto da Pessoa com Deficiência e a proteção conferida ao enfermo mental e ao deficiente mental

2.2.4.2.2. Critérios dogmáticos para a aplicação da Lei $13.146 / 2015$........................................................ 54

2.2.4.3. Análise dogmática da correlação entre a invalidade causada por incapacidade e o prejuízo causado ao incapaz 61

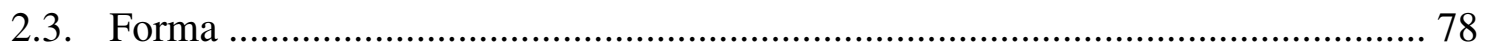

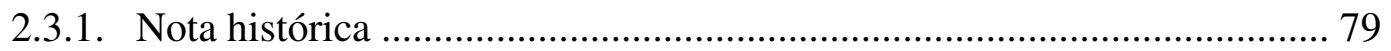

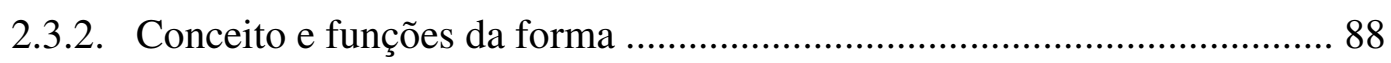

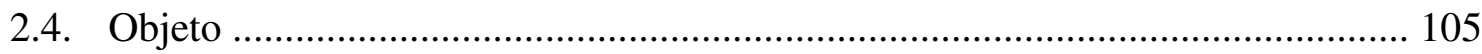


3.1. A invalidade como causa de ineficácia

3.1.1. A ineficácia do ato jurídico

3.1.2. Distinção entre invalidade e inexistência

3.2. Conceito e classificação da invalidade

3.2.1. Distinção entre efeitos do negócio jurídico nulo e efeitos da nulidade .. 136

3.2.2. Nulidade 138

3.3. Efeitos da invalidação 157

3.3.1. Âmbito de aplicação do artigo 182 do Código Civil 158

3.3.2. Análise da primeira parte do artigo 182 do Código Civil: o retorno ao statu quo ante 160

3.3.3. Análise da segunda parte do artigo 182 do Código Civil: situações de impossibilidade de restituição das partes ao statu quo ante 166

3.3.3.1. Pagamento feito a incapaz em razão de obrigação anulada 167

3.3.3.2. Restituição ou qualquer indenização que acarreta enriquecimento injustificado 169

3.3.3.3. Usucapião da coisa que seria objeto de restituição 172

3.3.3.4. Ex variis causarum figuris 178

3.4. Favor negotii - a conservação dos negócios jurídicos 180

3.4.1. Proteção a terceiros de boa-fé contra a ineficacização por nulidade 192

3.4.2. Ausência de violação do bem jurídico protegido pela norma jurídica que impôs a invalidação 202

3.4.3. Estabilização da eficácia de negócio jurídico celebrado por agente ilegítimo

3.4.4. Análise do artigo 105 do Código Civil 221

\section{Capítulo 4 - Aspectos processuais da invalidade: breves considerações} 225

4.1. Delimitação dos aspectos processuais relevantes à análise da categoria jurídica da invalidade disciplinada pelo Código Civil 225

4.2. Natureza jurídica do provimento jurisdicional que reconhece a invalidade do ato jurídico preceptivo 226

4.3. Legitimidade ativa ad causam para as ações de invalidade 235 
4.4. Limites subjetivos da extensão da coisa julgada em ação de invalidade 250

Conclusão 255

Bibliografia 


\section{INTRODUÇÃO}

Como o título do presente trabalho indica, propõe-se analisar dogmaticamente a categoria jurídica da invalidade tal qual tratada pelo Código Civil brasileiro. Qualifica-se a análise de dogmática porque, com ela, pretende-se descrever quais são as soluções que o Código Civil brasileiro oferece aos problemas decorrentes da invalidade, e não propor soluções inovadoras - tarefa do legislador - ou próprias de outros sistemas jurídicos.

A análise proposta, por ser dogmática, portanto, tem por único objetivo colaborar com a decidibilidade ${ }^{1}$ de casos concretos e, para tanto, buscar-se-á fixar o sentido de algumas expressões equívocas utilizadas pelo legislador, bem como expor algumas contradições doutrinárias que têm sido causa de repetição irrefletida de dogmas que não se sustentam à luz do direito positivo pátrio.

Como não se estão a questionar as regras do direito positivo - senão algumas suas interpretações -, e, sim, partindo-se delas, poder-se-á julgar as soluções apresentadas como corretas ou incorretas. Será tida por correta se puder ser reconduzida coerentemente a alguma regra do Código Civil; do contrário, haverá de ser tida por incorreta.

O plano de trabalho que se pretende seguir consiste em dois momentos lógicos distintos: no primeiro, são apresentadas construções dogmáticas acerca da categoria jurídica da invalidade; no segundo, são analisadas, a partir do instrumental teórico obtido, regras do Código Civil que direta ou indiretamente tratam da invalidade, buscando, com isso, conferir-lhes interpretação coerente com as finalidades que lhe são tradicionalmente atribuídas pela dogmática do Direito Civil.

Quanto ao primeiro momento lógico, a construção teórica passará pelas seguintes estapas:

\footnotetext{
${ }^{1}$ FERRAZ JUNIOR, Tércio Sampaio. Introdução ao estudo do direito: técnica, decisão, dominação. 6. ed. rev. e amp. São Paulo: Atlas, 2003, p. 63.
} 
No primeiro capítulo, defende-se que a invalidade é consequência do exercício irregular da autonomia privada e que, portanto, é qualificação própria de atos jurídicos preceptivos (negócios jurídicos e atos jurídicos em sentido estrito), devendo ser analisada à luz desta categoria específica de fato jurídico.

No segundo capítulo, analisam-se a capacidade e a forma e, de modo incidental, o objeto do negócio jurídico. Defende-se que o Código Civil, ao arrolar os requisistos de validade em seu artigo 104, parte de uma clivagem implícita entre requistos de validade respeitantes à parte ou às partes negociais - justamente a capacidade e a forma - e requsitos de validade respeitantes a terceiros, designadamente os relativos ao objeto negocial. A partir desta distinção, justifica-se - já no terceiro capítulo - que o Código Civil comporta classificação da nulidade, e não da anulabilidade, em nulidade relativa e nulidade absoluta. Estar-se-á diante de nulidade relativa quando a causa da nulidade for a incapacidade (absoluta) e o descumprimento de regra relativa à forma; diante de nulidade absoluta, quando o objeto negocial for ilícito, impossível ou indeterminável.

No terceiro capítulo, busca-se fixar um conceito de invalidade para, distinguindo-a da inexistência, demonstrar que o ato jurídico preceptivo, embora nulo, produz efeitos. Diante da constatação de que há efeitos diretamente produzidos pelo ato jurídico preceptivo nulo, e já agora no segundo momento lógico da tese, busca-se oferecer respostas para as seguintes questões: (i) quais os efeitos do reconhecimento judicial da invalidade?; (ii) o juiz, ao aplicar o artigo 182 do Código Civil, deve observar quais balizas para determinar, ou não, o retorno das partes ao statu quo ante?; e, finalmente, (iii) a restituição pelo equivalente é a única medida que o juiz pode aplicar caso o retorno ao statu quo ante não seja possível?

A fim de responder a essas questões, parte-se de duas premissas: $1^{\text {a }}$ ) ao lado da distinção clássica entre ato jurídico nulo e ato jurídico anulável, é possível classificar o ato jurídico nulo em nulo absoluto e nulo relativo, o que influenciará, determinantemente, a legitimidade ativa para o reconhecimento da invalidade; $2^{a}$ ) pode-se extrair do sistema de invalidades previsto no Código Civil brasileiro regra que, preenchidos certos requisitos, permite a conservação dos efeitos de ato jurídico preceptivo nulo. Busca-se demonstrar 
essa regra a partir da construção histórica do favor testamenti, do qual a dogmática fez derivar a ideia mais ampla de favor negotii. Fundamentalmente, defende-se que as normas jurídicas que estabelecem as invalidades têm por objetivo tutelar certo interesse, e que, portanto, somente quando o interesse em questão foi ou possa vir a ser atingido poder-seão aplicar as consequências do reconhecimento da invalidade. Defende-se que a interpretação teleológica das normas sobre invalidade seja pautada pela noção de favor negotii.

Ainda, busca-se, de modo eminentemente exemplificativo, demonstrar algumas das potencialidades da construção teórica para a interpretação e, consequentemente, solução de alguns dos muitos problemas que a questão da invalidade suscita.

Em apertada síntese, a tese consiste em: primeiro, demonstrar que o ato jurídico preceptivo nulo produz efeitos; segundo, demonstrar que o juiz somente estará autorizado a aplicar as consequências da invalidade se o interesse tutelado pela norma jurídica impositiva da invalidade foi ou possa vir a ser atingido; terceiro, uma vez demonstrado que foi atingido o interesse tutelado pela norma, fornecer critérios para que o juiz aplique o artigo 182 do Código Civil. 


\section{CONCLUSÃO}

O objetivo da tese foi o de analisar dogmaticamente a categoria jurídica da invalidade no âmbito do Código Civil brasileiro, fundamentalmente, colocando à prova tradicionais dogmas do direito civil relativos ao negócio jurídico e, para que ela pudesse merecer a qualificação de dogmática, procurou-se sempre fundamentar suas afirmações e conclusões no direito positivo brasileiro e, também, na construção doutrinária que o teve por objeto.

Para que se pudesse desenvolver o estudo proposto, foi necessário reafirmar e justificar algo que, há algum tempo, bem poderia ser tido por óbvio: o negócio jurídico é o principal instrumento da autonomia privada, a qual consiste em uma das mais - senão mesmo na mais - importantes facetas da liberdade.

Se é verdade que a autonomia sempre foi alvo de negação por alguns pensadores - designadamente pelos chamados filósofos deterministas -, é igualmente verdadeiro que o Direito sempre a teve por pressuposto, até mesmo porque, do contrário, careceria de um mínimo de justificação moral.

Isso, como é evidente, não significa que a autonomia privada não haja sofrido e sofra ataques de juristas - no mais das vezes, de matiz estatizante -, podendo-se apontar como exemplo, embora indireto, de oposição a ela a negação da utilidade do conceito de negócio jurídico.

A oposição de alguns importantes juristas brasileiros, muitas vezes influenciados por tendências doutrinárias alienígenas, à utilidade da categoria negócio jurídico, não impediu que o Código Civil de 2002 dedicasse a ela Título exaustivo, em uma reafirmação importante do valor da autonomia privada. 
A autonomia privada, contudo e, talvez, infelizmente, não é daquelas categorias que, uma vez consagradas pela evolução histórico-axiológica ${ }^{677}$, podem ser atribuídas indistintamente a todos os cidadãos de um Estado, ao contrário, ela pressupõe a existência de um conjunto de características de base orgânica, o qual é condição de possibilidade para que um processo deliberativo possa ser qualificado como minimamente racional.

Assim, e por paradoxal que pareça, proclamar a autonomia privada de quem não disponha minimamente dessa condição de possibilidade, dispensando, pois, a estrutura de seu significado, implica, ideologicamente, negar o valor da autonomia e disso decorre uma consequência tão óbvia quanto inevitável: a pretexto de se negar a distinção entre pessoas autônomas e pessoas não autônomas, acaba-se por negar a necessidade de proteção destas face àquelas.

A autonomia privada é uma categoria do pensamento jurídico e, como tal, é natural que sofra alterações conceituais pelo Zeitgeist, porém, sob pena de sua desnaturação, seu núcleo significativo e sua natureza jurídica hão de ser preservadas. Quanto ao seu núcleo significativo, grosso modo, ele é composto pelas condições de possibilidade, tanto orgânicas, quanto materiais, de deliberação e escolha; quanto à sua natureza jurídica, é a de fonte do direito privado.

Foi a partir da premissa fundamental de que a autonomia privada é a fonte mais importante do direito privado que se procurou desenvolver a tese que ora se conclui.

Dessa premissa, é consequência lógica que a invalidação, é dizer, a supressão retroativa do produto de um negócio jurídico, implica limitar o exercício da autonomia privada, o que há de ser medida excepcional, justificada racionalmente ${ }^{678}$.

Defende-se nesta tese que a racionalidade da justificativa não se satisfaz com o mero juízo de adequação formal entre dado suporte fático concreto e o texto da

${ }^{677}$ REALE, Miguel. Direito natural/ direito positivo. São Paulo: Saraiva, 2012, p. 16.

678 Como ao longo de sua obra demonstrou Antonio Junqueira de Azevedo. Confira-se, fundamentalmente, Negócio jurídico: existência, validade e eficácia. 4. ed. São Paulo: Saraiva, 2002, p. $66 / 67$. 
norma jurídica impositiva da invalidade, algo que, embora necessário, não é suficiente à invalidação. Para tanto, é fundamental que o intérprete constate que, de fato, o negócio jurídico concreto que se pretende invalidar violou a finalidade da norma impositiva da sanção invalidante.

Essa constatação, isto é, esse controle de racionalidade, é facilitado pela sólida construção doutrinária sobre as normas jurídicas impositivas de invalidade, como as normas sobre capacidade, objeto e forma do negócio jurídico.

Defende-se, então, que ineficacizar, à causa de invalidade, um negócio jurídico sem que estejam presentes formal e materialmente as razões da invalidação é, pois, ilógico e arbitrário.

É ilógico porque carece de qualquer sentido fundamentar e sistematizar as razões de ser de uma norma impositiva de um requisito de validade se, quando da análise de um negócio jurídico concreto, for possível invalidá-lo sem sua aferição; arbitrário, insista-se, porque implicará limitar a autonomia privada sem justificativa racional.

Assim, um dos objetivos da tese foi o de demonstrar que a afirmação da autonomia privada passa, necessariamente, tanto pela garantia de seus meios, como pela tutela de seus resultados.

Um outro objetivo da tese foi o de buscar contribuir para o fornecimento de critérios dogmáticos para a aplicação do artigo 182 do Código Civil. A construção desses critérios exigiu o enfrentamento de um dogma assaz difundido: o de que o negócio jurídico nulo não produz efeitos.

Se, de fato, o negócio jurídico nulo não produzisse efeitos, não haveria qualquer dificuldade em sua ineficacização, ou melhor, sequer haveria qualquer necessidade disso. Porém, não é o que se dá.

O negócio jurídico nulo - e não apenas o anulável - ordinariamente produz efeitos jurídicos (confira-se, uma vez mais, o texto do parágrafo único do artigo 168 do 
Código Civil, no qual se faz expressa referência a efeitos - jurídicos, pois - do negócio jurídico nulo, além dos outros exemplos citados ao longo da tese), o que impõe ao intérprete a tarefa de conciliar o artigo 182 do Código Civil com outras de suas normas, como as que vedam o enriquecimento injustificado, disciplinam a usucapião e impõem a tutela de terceiros de boa-fé.

O objetivo da tese foi o de contribuir para a solução de casos concretos, seja fornecendo algum fundamento racional para a preservação do negócio jurídico, seja fornecendo critérios para sua ineficacização quando a invalidação for inevitável. 


\section{BIBLIOGRAFIA}

ABREU FILHO, José. O negócio jurídico e sua teoria geral. 5. ed. São Paulo: Saraiva, 2003.

ACCARIAS, G. Précis de droit romain. tome II. 4. ed. Paris: Cotillon, 1891.

AGUIAR JUNIOR, Ruy Rosado. Extinção dos contratos por incumprimento do devedor: resolução. Rio de Janeiro: Aide, 1991.

ALMEIDA, Guilherme Assis; BITTAR, Eduardo C. B. Curso de filosofia do direito. 2. ed. São Paulo: Atlas, 2002.

ALVES, José Carlos Moreira. Direito romano. v. 1. 7. ed. rev. e aum. Rio de Janeiro: Forense. 1990.

v. 2. 4. ed. Rio de Janeiro: Forense, 1986.

ALVIM, Agostinho. Da compra e venda e da troca. São Paulo: Forense, 1961.

Da doação. São Paulo: Revista dos Tribunais, 1963.

ALVIM, Arruda; MONTEIRO, Estela L.; CAMARGO, Soares de. Ação declaratória: ementário de doutrina e jurisprudência. São Paulo: Revista dos Tribunais, 1984.

AMARAL, Francisco. Direito civil: introdução. 7. ed. Rio de Janeiro: Renovar, 2006.

Direito civil: introdução. 8. ed. Rio de Janeiro: Renovar, 2014.

ANDRADE, Manuel Domingues de. Teoria geral da relação jurídica. v. 2. 9. reimp. Coimbra: Almedina, 2003.

APRIGLIANO, Ricardo de Carvalho. Ordem pública e processo: o tratamento das questões de ordem pública no direito processual civil. São Paulo: Atlas, 2011. Coleção Atlas de Processo Civil. Coordenação: Carlos Alberto Carmona.

ARISTÓTELES. Ética a Nicômaco. Tradução Edson Bini. 3. ed. Bauru: Edipro, 2009.

ASCENSÃO, José de Oliveira. Direito civil: teoria geral. v. 1. 3. ed. São Paulo: Saraiva, 2010 .

ASCENSÃO, José de Oliveira. Direito civil: teoria geral. v. 2. São Paulo: Saraiva, 2010. 
Introdução à ciência do direito. 3. ed. rev. e atual. Rio de Janeiro: Renovar, 2005.

ASSIS, Araken de. Resolução do contrato por inadimplemento. 2. ed. rev. e atual. São Paulo: Revista dos Tribunais, 1994.

; ANDRADE, Ronaldo Alves de. ALVES, Francisco Glauber Pessoa. Comentários ao Código Civil brasileiro. v. 5. Rio de Janeiro: Forense, 2007.

ÁVILA, Humberto. Segurança jurídica no direito tributário. Tese (Titularidade). São Paulo: FDUSP, 2009.

AZEVEDO, Álvaro Villaça. Comentários ao novo Código Civil. v. 7. Rio de Janeiro: Forense, 2005.

AZEVEDO, Antonio Junqueira de. Negócio jurídico e declaração negocial: noções gerais e formação da declaração negocial. Tese (Titularidade). São Paulo: FDUSP, 1986.

. Negócio jurídico: existência, validade e eficácia. 4. ed. São Paulo: Saraiva, 2002. . Estudos e pareceres de direito privado. São Paulo: Saraiva, 2004.

; TÔRRES, Heleno Taveira; CARBONE, Paulo (coord.). Princípios do Novo Código Civil Brasileiro e Outros Temas, Homenagem a Tullio Ascarelli. São Paulo: Quartier Latin, 2008.

Forma (negócios jurídicos). In: Enciclopédia Saraiva do Direito. v. 38. Rubens Limongi França (coord.). São Paulo: Saraiva, 1977.

BAPTISTA, Francisco de Paula. Compêndio de hermenêutica jurídica. Alcides Tomasetti Junior (coord.). São Paulo: Saraiva, 1984.

BARBOSA, Heloisa Helena; TEPEDINO, Gustavo; MORAES, Maria Celina Bodin de. Código Civil interpretado conforme a Constituição da República. v. 1. 2. ed. rev. e atual. Rio de Janeiro: Renovar, 2007.

BDINE JUNIOR, Hamid Charaf. Efeitos do negócio jurídico nulo. São Paulo: Saraiva, 2010.

BESSONE, Darcy. Direitos reais. São Paulo: Saraiva, 1988. 
BETANCOURT, Fernando. Derecho romano clásico. Sevilla: Universidad del Sevilla, 2001 .

BETTI, Emilio. Teoria generale del negozio giuridico. Napoli: Edizioni Scientifiche Italiane, 2002.

et al. Teoría general del negocio jurídico. Perú: ARA Editores, 2001.

Interpretação da lei e dos atos jurídicos. Tradução Karina Jannini. São Paulo:

Martins Fontes, 2007.

BEVILAQUA, Clóvis. Código Civil dos Estados Unidos do Brasil comentado. 11. ed. atual. por Achilles Bevilaqua e Isaias Bevilaqua. v. 1. Rio de Janeiro: Francisco Alves, 1956.

BEVILÁQUA, Clóvis. Código Civil dos Estados Unidos do Brasil comentado. v. 3. Rio de Janeiro: Francisco Alves, 1955, p. 13.

v. 4. 10. ed. atual. por Achilles Bevilaqua e Isaias Bevilaqua. Rio de Janeiro: Francisco Alves, 1955.

Teoria geral do direito civil. 3. ed. rev. e atual. por Caio Mário da Silva Pereira. Rio de Janeiro: Francisco Alves, 1980.

BIANCA, Massimo. Diritto civile. v. 3. Milano: Giuffrè, 2000.

BIONDI, Biondo. Istituzioni di diritto romano. Milano: Giuffré, 1952.

BITTAR, Eduardo C. B. Curso de filosofia aristotélica: leitura e interpretação do pensamento aristotélico. Barueri: Manole, 2003.

; ALMEIDA, Guilherme Assis. Curso de filosofia do direito. 2. ed. São Paulo: Atlas, 2002.

BOBBIO, Norberto. Teoria Geral do Direito. Tradução Denise Agostinetti. 3. ed. São Paulo: Martins Fontes, 2010.

BONFANTE, Pietro. Instituciones de derecho romano. Tradução Luis Bacci e Andrés Larrosa. Madrid: REUS, 1951.

BUCKLER, William $\mathrm{H}$. The origin and history of contract in roman law down to the end of the republican period. Londres: Cambridge University Press, 1895. 
BUNAZAR, Maurício. Elementos para uma análise unitária do fenômeno da invalidade. In: JUSTO, A. Santos et al. Direito civil constitucional e outros estudos em homenagem ao Prof. Zeno Veloso. coord. Pastora do Socorro Teixeira Leal. Rio de Janeiro: Forense, 2014. Notas sobre a interpretação do art. 453 do Código Civil. Revista Síntese Direito Civil e Processual Civil, São Paulo, v. 90, jul./ago. 2014.

Interpretação (hermenêutica). In: LAGRASTA NETO, Caetano; SIMÃO, José Fernando (coord.). Dicionário de direito de família. v. 2. São Paulo: Atlas, 2015, p. 560562.

BUZAID, Alfredo. Ação declaratória no direito brasileiro. São Paulo: Saraiva, 1986.

CALDAS AULETE. Dicionário contemporâneo da língua portuguesa. ed. atual., rev. e aum. por Hamílcar de Garcia e Antenor Nascentes. vol. 2. Rio de Janeiro: Delta, 1958.

CAPITANT, Henri; COLIN, Ambroise. Cours élémentaire de droit civil. tome II. augmenté par Julliot de la Morandière. Paris: Dalloz, 1953.

CARNEIRO, Manuel Borges. Direito civil de Portugal. v. 3. Lisboa: Sousa Neves, 1867. v. 2. Lisboa: Sousa Neves, 1867.

CARNELUTTI, Francesco. Teoria giuridica della circolazione. Padova: CEDAM, 1933. . Teoria geral do direito. Tradução A. Rodrigues Queiró e Artur Anselmo de Castro. Rio de Janeiro: Âmbito Cultural, 2006.

CARVALHO, Francisco Pereira de Bulhões. Sistemas de nulidades dos atos jurídicos. Rio de Janeiro: Forense, 1980.

CARVALHO, Paulo de Barros. Curso de direito tributário. 24. ed. São Paulo: Saraiva, 2012 .

CASELLA, Mario. Nullità parziale del contratto e inserzione automatica di clausole. Milano: Giuffrè, 1974.

CASTRO, Torquato. Legitimação (direito material). In: LIMONGI FRANÇA, Rubens (coord.). Enciclopédia Saraiva do direito. v. 48. São Paulo: Saraiva, 1977. Ação declaratória. 2. ed. São Paulo: Saraiva, 1942. 
CERAMI, Pietro et al. Ordinamento costituzionale e produzione del diritto in Roma antica. Napoli: Jovene editore, 2006.

CHIOVENDA, Giuseppe. Instituições de direito processual civil. 4. ed. Tradução Paolo Capitanio. Campinas: Bookseller, 2009.

CHIRONI; ABELLO. Tratatto di diritto civile italiano. v. 1. Parte generale. Torino: Fratelli Bocca, 1904.

CÍCERO, Marcus Tullius. De fato, XVIII, 41. Traduzido para o francês por Vincent Ravasse, l’Université de Québec, 2002.

CINTRA, Antonio Carlos de Araújo; GRINOVER, Ada Pellegrini; DINAMARCO, Cândido Rangel. Teoria geral do processo. 24. ed. rev. e atual. São Paulo: Malheiros, 2008 .

COLIN, Ambroise; CAPITANT, Henri. Cours élémentaire de droit civil. v. 2. aum. por Julliot de la Morandière. Paris: Dalloz, 1953.

COMPARATO, Fábio Konder. Ensaios e pareceres de direito empresarial. Rio de Janeiro: Forense, 1978.

COMTE-SPONVILLE, André. Dicionário Filosófico. São Paulo: Martins Fontes, 2003.

CORBINO, Alessandro. Il formalismo negoziale nell'esperienza romana. Milano: Giuffrè, 2000 .

CORDEIRO, António Menezes. Tratado de direito civil português. v. 1. t. 1. 3. ed. Coimbra: Almedina, 2007.

. v. 1. t. 4., reimpressão da ed. de maio/2005. Coimbra: Almedina, 2007. v. 2. t. 3. Coimbra: Almedina, 2010. v. 2. 4. ed. Coimbra: Almedina, 2014.

Da modernização do direito civil. v. 1. Coimbra: Almedina, 2004.

Da boa fé no direito civil. Coimbra: Almedina, 2011.

CORNIL, J. Droit Romain. Bruxelles: Bruylant-Christophe, 1885. 
CORRAL, Ildefonso Garcia del. Cuerpo del derecho civil romano. v. 2. Barcelona: Jaime Molinas, 1892.

v. 3. Barcelona: Jaime Molinas, 1897.

CORREIA, Alexandre; SCIASCIA, Gaetano. Manual de direito romano e textos em correpondência com os artigos do Código Civil brasileiro. v. 1. 2. ed. São Paulo: Saraiva, 1953.

CRISCUOLI, Giovanni. La nullità parziale del negozio giuridico. Milano: Giuffrè, 1959.

CRUZ, José Raimundo Gomes da. Pluralidade de partes e intervenção de terceiros. São Paulo: Revista dos Tribunais, 1991.

CUMYN, Michelle. La validité du contrat suivant le droit strict ou l'équité: étude historique et comparée des nullités contractuelles. Paris: L.G.D.J., 2002.

D'ENTRÈVES, Alessandro Passerin. Il negozio giuridico: saggio di filosofia del diritto. Torino: Roberto Gayet, 1934.

DEL NERO, João Alberto Schültzer. Conversão substancial do negócio jurídico. Rio de Janeiro: Renovar, 2001.

DERZI, Misabel de Abreu Machado. Direito tributário, direito penal e tipo. 2. ed. rev. e ampl. São Paulo: Revista dos Tribunais, 2007.

DÍAZ, Julio Alberto. Para uma nova hermenêutica dos intervalos lúcidos. In: PEREIRA, Rodrigo da Cunha (coord.). Repensando o direito de família: Anais do I Congresso Brasileiro de Direito de Família. Belo Horizonte: Del Rey, 1999.

DIDIER JUNIOR, Fredie. Curso de direito processual civil. v. 1. 17. ed. rev., amp. e atual. Salvador: Jus Podivm, 2015.

DÍEZ-PICAZO, Luis. La representación el el derecho privado. Madrid: Civitas, 1979.

DINAMARCO, Cândido Rangel. Instituições de direito processual civil. v. 2. São Paulo: Malheiros, 2009.

DINIZ, Maria Helena. Curso de direito civil brasileiro. v. 1. São Paulo: Saraiva, 2014. Lei de introdução ao Código Civil brasileiro interpretada. 9. ed. São Paulo: Saraiva, 2002. 
. Curso de direito civil brasileiro. v. 3. 30. ed. São Paulo: Saraiva, 2014.

DOMAT, Jean. Les loix civiles dans leur ordre naturel. v. 2. 2. ed. Paris: Pierre Emery, 1697.

DORAL, Josè Antonio; ARCO, Miguel Angel del. El negocio juridico. Madrid: Trivium, 1982.

EBERLE, Simone. A capacidade entre o fato e o direito. Porto Alegre: Sergio Antonio Fabris Editor, 2006.

ECO, Umberto. Os limites da interpretação. Tradução Pérola de Carvalho. São Paulo: Perspectiva, 2010.

ENNECCERUS, Lugwig; KIPP, Theodor; WOLFF, Martín. Tratado de derecho civil. v. 2. Tradução Blas Pérez González e José Alguer. Barcelona: Bosch, 1935. t. 4. v. 1. Barcelona: Bosch, 1953.

ESPÍNOLA, Eduardo; ESPÍNOLA FILHO, Eduardo. A lei de introdução do Código Civil brasileiro. v. 1. 3. ed. atual por Silva Pacheco. Rio de Janeiro: Renovar, 1999.

FARIAS, Cristiano Chaves de; ROSELVALD, Nelson. Direito civil: teoria geral. 9. ed. Rio de Janeiro: Lumen Juris, 2011.

FAZIO, Eugenio. Dalla forma alle forme. Struttura e funzione del neoformalismo negoziale. Milano: Giuffrè, 2011.

FERRARA, Luigi Cariota. Il negozio giuridico nel diritto privato italiano. Napoli: Edizione Scientifiche Italiane, 2011.

FERRARA, Francesco. Il negozio giuridico nel diritto privato italiano. Napoli, Edizioni Scientifiche Italiane, 2011.

FERRAZ JUNIOR, Tércio Sampaio. Introdução ao estudo do direito: técnica, decisão, dominação. 6. ed. rev. e amp. São Paulo: Atlas, 2010.

Teoria da norma jurídica. 4. ed. Rio de Janeiro: Forense, 2009.

FERREIRA, Aurélio Buarque de Holanda. Novo dicionário Aurélio da língua portuguesa. 4. ed. Curitiba: Positivo, 2009.

FERRI, Luigi. L'autonomia privata. Milano: Giuffrè, 1959. 
FERRI, Giovanni B. Il negozio giuridico. 2. ed. Milano: CEDAM, 2004.

FIGUEIREDO, Gabriel Seijo Leal de. Da representação. In: LOTUFO, Renan; NANNI, Giovanni Ettore (coord.). Teoria geral do direito civil. São Paulo: Atlas, 2008.

FIUZA, César. Direito civil. 18. ed. rev., atual. e ampl. São Paulo: Revista dos Tribunais, 2015 .

FLUME, Werner. El negocio juridico. Tradução José María Miguel González e Esther Gómez Calle. Madrid: Fundación cultural del notariado, 1998.

FRANÇA, Rubens Limongi. Enciclopédia Saraiva do Direito. v. 38. Rubens Limongi França (coord.). São Paulo: Saraiva, 1977. . Manual de direito civil. v. 1. 4. ed. São Paulo: Revista dos Tribunais, 1980.

FREITAS, Augusto Teixeira de. Esboço do Código Civil. v. 1. Brasília: Universidade de Brasília, 1983.

. Consolidação das Leis Civis. v. 1. ed. fac. sim. Brasília: Senado Federal, 2003. v. 2. ed. fac. sim. Brasília: Senado Federal, 2003.

GAINO, Itamar. Invalidade do negócio jurídico. In LOTUFO, Renan; NANNI, Giovanni Ettore (coord.). Teoria geral do direito civil. São Paulo: Atlas, 2008.

GAIO. Instituições de direito privado romano. Tradução J. A. Segurado e Campos. Lisboa: Calouste-Gulbenkian, 2010.

GALGANO, Francesco. El crepúsculo del negocio jurídico. In: BETTI, Emilio et alii. Teoría general del negocio jurídico. Perú: ARA Editores, 2001.

GARCEZ, Martinho. Nullidades dos actos jurídicos. Rio de Janeiro: Cunha \& Irmão, 1896. v. 1. 2. ed. Rio de Janeiro: Jacintho Ribeiro dos Santos, 1910.

GIORGI, Giorgio. Teoria de las obligaciones en el derecho moderno. v. 3. Tradução Eduardo Dato Iradier. Madrid: REUS, 1929.

GOMES, Orlando. Novos temas de direito civil. Rio de Janeiro: Forense, 1983. 
Introdução ao direito civil. Atual. por Theodoro Humberto Junior. 12. ed. Rio de Janeiro: Forense, 1996.

. Contratos. 26. ed. atual. por Antonio Junqueira de Azevedo e Francisco Paulo de Crescenzo Marino. Rio de Janeiro: Forense, 2007.

GONÇALVES, Carlos Roberto. Direito civil brasileiro. v. 1. 13. ed. São Paulo: Saraiva, 2015 .

v. 3. 12. ed. São Paulo: Saraiva, 2015.

GONÇALVES, Luiz Cunha. Tratado de direito civil. v. 4. t. 1. 2. ed. atual. e aum. por Orozimbo Nonato, Laudo de Camargo e Vicente Ráo e anot. por R. Barbosa. São Paulo: Max Limonad, 1958.

. v. 4. t. 2. 2. ed. adap. por Orozimbo Nonato, Laudo de Camargo e Vicente Ráo e anot. por Jayme Landim. São Paulo: Max Limonad, 1958.

GROSSI, Paolo. A ordem jurídica medieval. Tradução Denise Rossato Agostinetti. São Paulo: Martins Fontes, 2014.

GUERRA, Alexandre. Princípio da conservação dos negócios jurídicos: a eficácia jurídico-social como critério de superação das nulidades negociais. São Paulo: Almedina, 2016.

GUZMÁN, Luis Aberto Peña; ARGÜELLO, Luis Rodolfo. Derecho romano. v. 1. Buenos Aires: TEA, 1962.

HART, H. L. A. O conceito de direito. Tradução Antônio de Oliveira Sette-Câmara. São Paulo: Martins Fontes, 2009.

HIRONAKA, Giselda Maria Fernandes Novaes. Contratos reais e o princípio do consensualismo. Revista da Faculdade de Direito da Universidade de São Paulo, São Paulo, vol. 84/85, 1989/1990, p. 79-91.

HUGO, Institutionen des heut. röm. Rechts, II, §29 apud STOLFI, Giuseppe. Teoria del negozio giuridico. Padova: CEDAM, 1947.

HULOT. Les cinquantes livres du Digeste ou Pandectes de l'Empereur Justinien. v. 1. Paris: Metz, 1803. 
HUME, David. Tratado da natureza humana. São Paulo: UNESP, 2009.

HUPKA, Josef. La representación voluntaria en los negocios jurídicos. Tradução Luis Sancho Seral. Madrid:Revista de derecho privado, 1930.

IGLESIAS, Juan. Direito romano. São Paulo: Revista dos Tribunais, 2012.

IRTI, Natalino. Idola libertatis: tre esercizi sul formalismo giuridico. Milano: Giuffrè, $19[? ?]$.

JOLIVET, Régis. Curso de filosofia. 3. ed. Tradução Eduardo Prado de Mendonça. Rio de Janeiro: Agir, 1957.

JOSSERAND, Louis. Cours de droit civil positif français. v. 2. Paris: Sirey, 1939.

JUSTO, A. Santos. Direito privado romano. v. 1. 2. ed. Coimbra: Coimbra Editora, 2003. v. 2. Coimbra: Coimbra Editora, 2003.

; et al. Direito civil constitucional e outros estudos em homenagem ao Prof. Zeno

Veloso. coord. Pastora do Socorro Teixeira Leal. Rio de Janeiro: Forense, 2014.

KANT, Immanuel. Prolegômenos a toda a metafísica futura. Lisboa: Edições 70, 2008.

Crítica da razão pura. Tradução Manuela Pinto dos Santos e Antonio Fradique Morujão. 7. ed. Lisboa: Fundação Calouste Gulbenkian, 2010.

Crítica da razão prática. Tradução, introdução e notas de Valerio Rohden. São Paulo: Martins Fontes, 2002.

KASER, Max. Direito privado romano. 2. ed. Tradução Samuel Rodrigues e Ferdinand Hämmerle. Lisboa: Fundação Calouste Gulbenkian, 2011.

KELSEN, Hans. Teoria pura do direito. Tradução João Baptista Machado. 3. ed. Coimbra: Armenio Amado, 1974.

KENNY, Anthony. Uma nova história da filosofia ocidental. v. 1. Traduzido por Carlos Alberto Bárbaro. São Paulo: Loyola, 2008.

KROETZ, Maria Cândida do Amaral. A representação voluntária no direito privado. São Paulo: Revista dos Tribunais, 1997. 
KRUEGER, Paulus Krueger; MOMMSEN, Theodorus. Corpus Iuris Civilis. v. 1. Institutiones. Digesta. 22. ed. Berlim: Weidmann, 1973.

KÜMPEL, Vitor Frederico. Teoria da aparência no Código Civil de 2002. São Paulo: Método, 2007.

LANDIM, Francisco. O credor aparente. São Paulo: HI, 1999.

LARENZ, Karl. Derecho civil: parte general. Tradução Miguel Izquierdo e MacíasPicavea Madrid: EDERSA, 1978.

LEITÃO, Luis Manuel Teles de Menezes. O enriquecimento sem causa no direito civil. Coimbra: Almedina, 2005.

LIEBMAN, Enrico Tullio. Eficácia e autoridade da sentença e outros escritos sobre a coisa julgada. Notas ao direito brasileiro vigente por Ada Pellegrini Grinover. Rio de Janeiro: Forense, 1981.

LIMA, Alvino. Fraude no direito civil. São Paulo: Saraiva, 1965.

LOBO, Paulo. Direito civil: parte geral. 4. ed. São Paulo: Saraiva, 2013.

LOBO, Paulo. Direito civil: contratos. São Paulo: Saraiva, 2011.

. Comentários ao Código Civil. v. 6. São Paulo: Saraiva, 2003.

LOPES, Miguel Maria de Serpa. Curso de direito civil. v. 1.8 ed. rev. e atual. por José Serpa Santa Maria. Rio de Janeiro: Freitas Bastos, 1996.

Comentário teórico e prático da Lei de Introdução ao Código Civil. v. 1. Rio de Janeiro: Jacintho Editora, 1943.

LOPEZ, Teresa Ancona. O estado de perigo como defeito do negócio jurídico. In: CASSETTARI, Christiano (coord.). 10 anos de vigência do Código Civil brasileiro de 2002: estudos em homenagem ao professor Carlos Alberto Dabus Maluf. São Paulo: Saraiva, 2013.

LOTUFO, Renan; NANNI, Giovanni Ettore (coord.). Teoria geral do direito civil. São Paulo: Atlas, 2008.

LUHMANN, Niklas. Il diritto della società. Tradução Luisa Avitabile. Torino: Giappichelli, 2012. 
MACCORMICK, Neil. Argumentação jurídica e teoria do direito. Tradução Waldéa Barcellos. São Paulo: Martins Fontes, 2006.

MAIA JUNIOR, Mairan Gonçalves. A representação no negócio jurídico. São Paulo: Revista dos Tribunais, 2001.

MALUF, Carlos Alberto Dabus. A inexistência na teoria das nulidades. Tese. São Paulo: FDUSP, 2001.

MARINO, Francisco Paulo de Crescenzo. Interpretação do negócio jurídico. São Paulo: Saraiva, 2011.

MARINONI, Luiz Guilherme; ARENHART, Sérgio Cruz. Processo de conhecimento. v. 2. 10. ed. São Paulo: Revista dos Tribunais, 2012.

MASSON, Nathalia. O princípio da liberdade das formas. In: MORAES, Maria Celina Bodin de. Princípios do direito civil contemporâneo. Rio de Janeiro: Renovar; 2006.

MATTIA, Fabio Maria de. Aparência de representação. São Paulo: CID, 1999.

MAXIMILIANO, Carlos. Hermenêutica e aplicação do direito. 19. ed. Rio de Janeiro: Forense, 2003.

MAY, Gaston. Éléments de droit romain. 18. ed. Paris: Sirey, 1932.

MELLO FREIRE, Pascoal José de. Institutiones juris civilis lusitani cum publici tum privati, Liv. II. Coimbra: 1845.

MELO, Marco Aurélio Bezerra de. Novo Código Civil anotado. v. 3. 2. ed. rev., ampl. e atual. Rio de Janeiro: Lumen Juris, 2004.

MELLO, Marcos Bernardes de. Teoria do fato jurídico: plano da existência. 13. ed. São Paulo: Saraiva, 2007.

Teoria do fato jurídico: plano da validade. 7. ed. São Paulo: Saraiva, 2011.

. Teoria do fato jurídico: plano da eficácia. $1^{\mathrm{a}}$ Parte. 3. ed. rev. São Paulo: Saraiva, 2007.

MENDONÇA, Carvalho de. Doutrina e prática das obrigações. v. 2. 3. ed. aum. e atual. por J. M. de Carvalho Santos. Rio de Janeiro: Forense, 1938. 
MICHELON JUNIOR, Cláudio. Ensaio sobre a história, as possibilidades e os limites de uma teoria das invalidades dos atos jurídicos. Revista do Ministério Público do Estado do Rio Grande do Sul, Porto Alegre, v. 40, 1998.

Direito restituitório. São Paulo: Revista dos Tribunais, 2007.

MICHAUD-QUANTIN, P. Expressions du mouvement communautaire dans le Moyen Âge latin. Paris: Universitas, 1970.

MIRANDA, Custódio da Piedade Ubaldino. Teoria geral do negócio jurídico. São Paulo: Atlas, 2009.

MIRANDA, F. C. Pontes de. Tratado de direito privado. v. 1. Rio de Janeiro: Borsoi, 1954.

MIRANDA, F. C. Pontes de. Tratado de direito privado. v. 1. 3. ed. Rio de Janeiro: Borsoi, 1970.

. v. 3. Rio de Janeiro: Borsoi, 1954.

. v. 4. 2. ed. Rio de Janeiro: Borsoi, 1954.

v. 4. 3. ed. Rio de Janeiro: Borsói, 1970.

. v. 5. Rio de Janeiro: Borsoi, 1955.

. v. 7. 3. ed. Rio de Janeiro: Borsói, 1971.

v. 25. Rio de Janeiro: Borsoi, 1959.

_v. 39. 3. ed. São Paulo: Borsoi, 1972.

.v. 42. 3. ed. São Paulo: Borsoi, 1972.

_. v. 46. 3. ed. Rio de Janeiro: Borsoi, 1972.

. v. 57. 3. ed. Rio de Janeiro: Borsói, 1973.

Tratado das ações. v. 2. São Paulo: Revista dos Tribunais: 1971.

v. 3. São Paulo: Revista dos Tribunais, 1972.

. v. 4. São Paulo: Revista dos Tribunais, 1973 
MONIER, Raymond. Manuel élémentaire de droit romain. v. 2. 4. ed. Paris: DomatMontchrestien, 1948.

MONTEIRO, Washington de Barros; PINTO, Ana Cristina de Barros Monteiro França. Curso de direito civil. v. 1. 42. ed. São Paulo: Saraiva, 2009. v. 1. 35. ed. São Paulo: Saraiva, 1997. v. 5. 32. ed. rev. e atual. por Ana Cristina de Barros Monteiro França Pinto. São Paulo: Saraiva, 2000.

MORAES, Maria Celina Bodin de; TEPEDINO, Gustavo; BARBOSA, Heloisa Helena. Código Civil interpretado conforme a Constituição da República. v. 1. 2. ed. rev. e atual. Rio de Janeiro: Renovar, 2007.

MORAES FILHO, Evaristo de. Sucessão nas obrigações e teoria da empresa. v. 1. Rio de Janeiro: Forense, 1960.

MOREIRA, Guilherme Alves. Instituições do direito civil português. v. 1. Coimbra: Imprensa da Universidade, 1907.

MOSCO, Luigi. La rappresentanza volontaria nel diritto privato. Napoli: Eugenio Jovene, 1961.

NANNI, Giovanni Ettore. Enriquecimento sem causa. 3. ed. São Paulo: Saraiva, 2012.

NERY, Rosa; NERY JR., Nelson. Instituições de direito civil. v. 1. t. 2. São Paulo: Revista dos Tribunais, 2015.

NEVES, Daniel Amorim Assumpção. Novo Código de Processo Civil comentado artigo por artigo. Salvador: Jus Podivm, 2016.

OLIVEIRA, A. de Almeida. O benefício de restituição 'in integrum'. Rio de Janeiro: Garnier, 1886.

OLIVEIRA, Arthur Vasco Itabaiana de. Tratado de direito das sucessões. v. 1. São Paulo: Max Limonad, 1952.

OLIVEIRA, J. M. Leoni Lopes de. Novo Código Civil anotado. v. 1. Rio de Janeiro: Lumen Juris, 2004. 
PACIFICI-MAZZONI, Emidio. Istituzioni di diritto civile italiano. v. 3. t. 2. Firenze: G. Pellas, 1869.

PARÁ FILHO, Tomás. Estudo sobre a sentença constitutiva. São Paulo: Obelisco, 1973.

PENTEADO, Luciano de Camargo. Efeitos contratuais perante terceiros. São Paulo: Quartier Latin, 2007.

Direito das coisas. 2. ed. rev., atual. e ampl. São Paulo: Revista dos Tribunais, 2012.

Doação com encargo e causa contratual. Campinas: Millennium, 2004.

PEREIRA, Caio Mário da Silva. Instituições de direito civil. v. 1. 12. ed. Rio de Janeiro: Forense, 1990.

PEREIRA, Rodrigo da Cunha (coord.). Repensando o direito de família: Anais do I Congresso Brasileiro de Direito de Família. Belo Horizonte: Del Rey, 1999.

PERLINGIERI, Pietro. Perfis do direito civil: introdução ao direito civil constitucional. 3. ed. Tradução Maria Cristina De Cicco. Rio de Janeiro: Renovar, 2007.

PETIT, Eugène. Tratado elementar de direito romano. Tradução Jorge Luís Custódio Porto. Campinas: Russell, 2003.

PINTO, Carlos Alberto da Mota. Teoria geral do direito civil. 4. ed. por António Pinto Monteiro e Paulo Mota Pinto. Coimbra: Coimbra, 2005.

PINTO, Ana Cristina de Barros Monteiro França; MONTEIRO, Washington de Barros. Curso de direito civil. v. 1. 42. ed. São Paulo: Saraiva, 2009.

PLANIOL, Marcel; RIPERT, Georges. Traité pratique de droit civil français. v. 1. Atual. por René Savatier. Paris: LGDJ, 1925.

; __ _ ESMEIN, Paul. Droit civil français. v. 6. Paris: LGDJ, 1930.

PORTUGAL. Ordenações Filipinas. v. 3. ed. fac. sim. da 14. ed. Brasília: Senado Federal, 2004.

POTHIER, Robert Joseph. Traités des obligations. tome 1er. Paris: Debure, 1764.

PUTTI, Pietro Maria. La nullità parziale: diritto interno e comunitario. Napoli: Edizioni Scientifiche Italiane, 2002. 
PRATA, Ana. A tutela constitucional da autonomia privada. Coimbra: Almedina, 1982.

RAMOS, J. Arias. Derecho romano. v. 1. 6. ed. Madrid: EDERSA,1954. v. 2-III. 6. ed. Madrid: EDERSA, 19[??].

RÁO, Vicente. Ato jurídico. São Paulo: Max Limonad, 1961.

REALE, Miguel. Fontes e modelos do direito: para um novo paradigma hermenêutico. São Paulo: Saraiva, 1994. O direito como experiência. 2. ed. fac. sim. São Paulo: Saraiva, 2010.

REALE, Miguel. Teoria tridimensional do direito. 3. ed. rev. e atual. São Paulo: Saraiva, 1980.

Lições preliminares de direito. 22. ed. São Paulo: Saraiva, 1995.

Direito natural/ direito positivo. São Paulo: Saraiva, 2012, p. 56-57.

RIPERT, Georges. La règle morale dans les obligations civiles. 4ème. ed. Paris: Librairie générale de droit et de jurisprudence, 1949.

RIZZARDO, Arnaldo. Parte geral do Código Civil. 2. ed. Rio de Janeiro: Forense, 2003.

RODRIGUES, Silvio. Direito civil. v. 1. 32. ed. São Paulo: Saraiva, 2002.

. Dos vícios do consentimento. 3. ed. atual. São Paulo: Saraiva, 1989.

RODRIGUES JUNIOR, Otavio Luiz. Código Civil comentado. v. 6. t. 1. São Paulo: Atlas, 2008.

ROPPO, Vincenzo. Diritto privato. Torino: Giappichelli, 2010.

ROSELVALD, Nelson; FARIAS, Cristiano Chaves de. Direito civil: teoria geral. 9. ed. Rio de Janeiro: Lumen Juris, 2011.

ROSS, Alf. Direito e justiça. Tradução Edson Bini. 2. ed. Bauru: Edipro, 2007.

SANSEVERINO, Paulo de Tarso Vieira. Contratos inominados II. 2. ed. rev., atual. e ampl. São Paulo: Revista dos Tribunais, 2011.

SANTO AGOSTINHO. Diálogo sobre o livre arbítrio. Tradução e introdução Paula Oliveira e Silva. Edição bilíngue. Lisboa: Centro de Filosofia da Universidade de Lisboa, 2001. 
O livre-arbitrio. São Paulo: Paulus, 1995.

SANTOS, J. M. de Carvalho. Código Civil brasileiro interpretado. v. 2. 2. ed. Rio de Janeiro: Metrópole, 1936.

v. 3. 2. ed. Rio de Janeiro: Freitas Bastos, 1937.

SAVIGNY, Karl von. Le droit des obligations. v. 2. Tradução G. Gérardin et Paul Jozon. 2. ed. Paris: Ernest Thorin, 1873.

Traité de droit romain. v. 3. Tradução Ch. Guenoux. Paris: Firmin Didot, 1845.

SCHMIEDEL, Raquel Campani. Negócio jurídico: nulidades e medidas sanatórias. 2. ed. São Paulo: Saraiva, 1985.

SCHULZ, Fritz. Derecho Romano Clásico. Tradução José Santa Cruz Teigeiro. Bosch: Barcelona, 1960.

SCIASCIA, Gaetano; CORREIA, Alexandre. Manual de direito romano e textos em correpondência com os artigos do Código Civil brasileiro. v.1. 2. ed. São Paulo: Saraiva, 1953.

SILVA, Clóvis V. do Couto e. A obrigação como processo. Rio de Janeiro: FGV, 2006.

SILVA, Regina Beatriz Tavares da; FIUZA, Ricardo (coord.). Código Civil comentado. 9. ed. São Paulo: Saraiva, 2013.

SIMÃO, José Fernando. Direito civil: contratos. São Paulo: Atlas, 2011.

Responsabilidade civil do incapaz. São Paulo: Atlas, 2008.

Estatuto da Pessoa com Deficiência causa perplexidade (Parte 2). Disponível em: <http://www.conjur.com.br/2015-ago-07/jose-simao-estatuto-pessoa-deficiencia-trazmudancas>. Acesso em: 13.10.2016.

Venda de ascendentes a descendentes. Revista de Direito Civil Contemporâneo, São Paulo, ano 1, v. 1, out./dez. 2014.

. Prescrição e decadência: início dos prazos. São Paulo: Atlas, 2013.

SOHM, Rudolph. The Institutes of roman law. Tradução James Crawford Ledlie. Oxford: Clarendon Press, 1892. 
Instituciones de derecho privado romano. 17. ed. Tradução W. Roces. Madrid: Editorial Revista de Derecho Privado, 1936.

STANCIOLI, Brunello. Sobre a capacidade de fato da criança e do adolescente: sua gênese e desenvolvimento na família. In: Revista brasileira de direito de família, v. 2, 1999, Porto Alegre, IBDFAM.

STOLFI, Giuseppe. Teoria del negozio giuridico. Padova: CEDAM, 1947.

STOLZE, Pablo. Entrevista. Revista do IBDFAM, Belo Horizonte, n. 24, dez. 2015/jan. 2016, p. 6 .

STRECK, Lenio. Hermenêutica e princípios da interpretação constitucional. In: CANOTILHO, J. J. Gomes; MENDES, Gilmar F.; SARLET, Ingo W.; (coords.). Comentários à Constituição do Brasil. São Paulo: Saraiva/Almedina, 2013, p. 77.

TALAMANCA, Mario. Elementi di diritto privato romano. Milano: Giuffrè, 2001.

TARTUCE, Flávio. Manual de direito civil. Rio de Janeiro: Forense, 2016. Direito civil. v. 1. 11. ed. São Paulo: Método, 2015.

TELLES, José Homem Correa. Digesto portuguez. v. 3. Coimbra: Imprensa da Universidade, 1846.

TEPEDINO, Gustavo; BARBOSA, Heloisa Helena; MORAES, Maria Celina Bodin de. Código Civil interpretado conforme a Constituição da República. v. 1. 2. ed. rev. e atual. Rio de Janeiro: Renovar, 2007. ; __ _ . v. 2. Rio de Janeiro: Renovar, 2006.

THEODORO JÚNIOR, Humberto. Comentários ao novo código civil. Sálvio de Figueiredo Teixeira (coord.). v. 3. t. 1. 3. ed. Rio de Janeiro: Forense, 2006.

THONNARD, F.-J. Compêndio de História da Filosofia. Tradução Dr. Valente Pombo. São Paulo: Herder, 1953.

TISSOT, A. Les douzes livres du Code de l'Empereur Justinien. v. 2. 2. ed. Paris: Metz, 1807. 
TOMASETTI JUNIOR, Alcides. Ação resolutória. In: Enciclopédia Saraiva de direito. Rubens Limongi França (coord.). v. 3. São Paulo: Saraiva, 1977.

TOULLIER, C. B. M. Le droit civil français suivant l'ordre du Code. v. 7. Rennes: Cousin-Danelle, 1816.

TRABUCCHI, Alberto. Istituzioni di diritto civile. 6. ed. Padova: CEDAM, 1952.

TRIMARCHI, Pietro. Istituzioni di diritto privato. 19. ed. Milano: Giuffrè, 2011.

TUCCI, José Rogério Cruz e. Limites subjetivos da coisa julgada. São Paulo: Revista dos Tribunais, 2006.

VAN WETTER, Polynice. Pandectes contenant l'histoire du Droit Romain. v. 1. Paris: LGDJ, 1909. v. 4. Paris: LGDJ, 1910.

VELASCO, José I. C. Martínez de. La exteriorización de los actos jurídicos: su forma y la protección de su apariencia. Espanha: Bosch, 1990.

VELOSO, Zeno. Invalidade do negócio jurídico: nulidade e anulabilidade. 2. ed. Belo Horizonte: Del Rey, 2005.

VELOSO, Zeno. Comentários à lei de introdução ao Código Civil: artigos $1^{\circ}$ a $6^{\circ}$. 2. ed. rev. e aum. Belém: Unama, 2006.

VENOSA, Silvio de Salvo. Direito civil. v. 1. São Paulo: Atlas, 2013. v. 3. 13. ed. São Paulo: Atlas, 2013.

VIEIRA NETO, Manoel Augusto. Ineficácia e Convalidação. São Paulo: Max Limonad, $19[? ?]$.

VILANOVA, Lourival. Causalidade e relação no direito. 4. ed. São Paulo: Revista dos Tribunais, 2000.

VILLELA, João Baptista. Incapacidade transitória de expressão. In: AZEVEDO, Antonio Junqueira de; TÔRRES, Heleno Taveira; CARBONE, Paulo (coord.). Princípios do novo Código Civil brasileiro e outros temas: homenagem a Tullio Ascarelli. São Paulo: Quartier Latin, 2008.

VILLEY, Michel. Direito Romano. Tradução Fernando Couto. Resjuridica, Porto, 1955. 
Filosofia do direito: definições e fins do direito: os meios do direito. Tradução Márcia Valéria Martinez de Aguiar. 2. ed. São Paulo: Martins Fontes, 2008.

Questões de Tomás de Aquino sobre direito e política. Tradução Ivone C. Benedetti. São Paulo: Martins Fontes, 2014.

VON LINGENTHAL, Karl Zachariae. Le droit civil français. 1er. tome. Annoté, rétabli et traduit par MASSÉ et VERGÉ. Paris: Auguste Durand, 1854.

VON TUHR, Andreas. Derecho civil. v. 2. t. 1. Tradução Tito Ravà. Buenos Aires: Depalma, 1947. v. 3. t. 1. Tradução Tito Ravà. Buenos Aires: Depalma, 1947.

ZAKI, Magdi S. Le formalisme conventionnel: illustration de la notion de contrat-cadre. Revue internationale de droit comparé, vol. 38, n 4, oct./dec. 1986, p. 1045-1048.

ZANETTI, Cristiano de Sousa. A conservação dos contratos nulos por defeito de forma. São Paulo: Quartier Latin, 2013.

ZIMMERMANN, Reinhard. The law of obligations: roman foundations of the civilian tradition. Cape Town: Juta, 1992.

WATSON, Alan. Roman Law and Comparative Law. Athens: The University of Georgia Press, 1991.

WINDSCHEID, Bernard. Diritto delle pandette. Tradução Carlo Fadda e Paolo Emilio Bensa. v. 1. Torino: UTET, 1938. 